\title{
Genealogy construction in a historically isolated population: Application to genetic studies of rheumatoid arthritis in the Pima Indian
}

Jing-Ping Lin, $M D, P h D^{1}$, Rosemarie Hirsch, $M D, M P H^{l}$, Lennart T. H. Jacobsson, MD, PhD', William W. Scott, MD Loralie D. Ma, MD', Stanley R. Pillemer, $M D^{1}$, William C. Knowler, MD, DrPH ${ }^{4}$, Daniel L. Kastner, MD, PhD $D^{1}$, and Sherri J. Bale, $P h D^{l}$

\begin{abstract}
Purpose: Due to the characteristics of complex traits, many traits may not be amenable to traditional epidemiologic methods. We illustrate an approach that defines an isolated population as the "unit" for carrying out studies of complex disease. We provide an example using the Pima Indians, a relatively isolated population, in which the incidence and prevalence of Type 2 diabetes, gallbladder disease, and rheumatoid arthritis (RA) are significantly increased compared with the general U.S. population. A previous study of RA in the Pima utilizing traditional methods failed to detect a genetic effect on the occurrence of the disease. Methods: Our approach involved constructing a genealogy for this population and using a genealogic index to investigate familial aggregation. We developed an algorithm to identify biological relationships among 88 RA cases versus 4,000 subsamples of age-matched individuals from the same population. Kinship coefficients were calculated for all possible pairs of RA cases, and similarly for the subsamples. Results: The sum of the kinship coefficient among all combination of RA pairs, 5.92, was significantly higher than the average of the 4,000 subsamples, 1.99 ( $p$ $<0.001$ ), and was elevated over that of the subsamples to the level of second cousin, supporting a genetic effect in the familial aggregation. The mean inbreeding coefficient for the Pima was 0.00009 , similar to that reported for other populations; none of the RA cases were inbred. Conclusions: The Pima genealogy can be anticipated to provide valuable information for the genetic study of diseases other than RA. Defining an isolated population as the "unit" in which to assess familial aggregation may be advantageous, especially if there are a limited number of cases in the study population. Genetics in Medicine, 1999:1(5):187-193.
\end{abstract}

Key words: Genealogic approach, rheumatoid arthritis, kinship coefficient, inbreeding coefficient, Pima Indians

As many Mendelian traits are mapped and the responsible genes cloned, human geneticists are faced with new challengesthose complex traits that comprise a large portion of human disease. The term "complex trait" refers to any phenotype that does not exhibit classic, simple Mendelian inheritance. Examples include hypertension, most forms of diabetes, and the autoimmune diseases. For human diseases, the first step is often to carry out a genetic epidemiologic analysis to learn as much as possible about the pattern of occurrence in families and populations. For example, twin studies compare disease rates in monozygotic versus dizygotic twins; case-control studies analyze the risk of disease for a relative of an affected individual compared with the risk in the general population; and segre-

\footnotetext{
'National Instutute of Arthritis and Musculuskelitul and Skin Fiscases. National Institutes

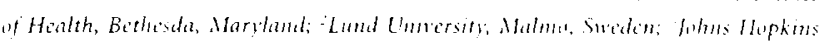

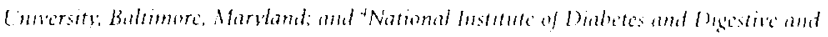
Kidney Discases. Nitional Institutes of Healh Phocuix, Arama

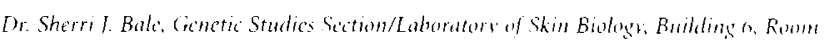
429/6 Center Dr. MSC 2757, Bethesele, MH 20892-275:

Revived: March 8,1990

Aciepted: /unt $\rightarrow 1990$
}

gation analysis involves fitting a series of models to the inheritance pattern of a trait in a pedigree or group of pedigrees. These approaches have yielded valuable information about traits that were caused by simple dominant or recessive genes. However, many complex traits may not be amenable to traditional genetic epidemiologic approaches. Samples for twin studies are difficult to collect when the disorder has very late onset. Case-control studies may fail to detect significant risks for diseases with a small relative risk for the genetic component as compared with environmental factors. Segregation analyses require the specific definition of a series of inheritance models, whereas the parameters for most complex traits are unknown. Additionally, complex traits are usually multifactorial in nature with age dependent penetrance, so that not all individuals can be readily characterized as "affected" or "not affected." For diseases of this nature, it is no longer sufficient or meaningful to ascertain probands as before, because everyone is at some level of risk of developing the disease. As a result, either random sampling of families must be done as in studies of blood pressure ${ }^{1}$ or whole populations must be surveyed. ${ }^{2}$

Genetically isolated founder populations are good samples on which to perform whole population surveys for a complex 
disorder. Usually they are well-defined and relatively genetically homogenous. Genetic studies of whole populations become practical if near total ascertainment is possible and genealogic information is available. Genealogic studies of isolated populations have been shown to have great benefits in studies of complex diseases. In particular, this approach has been used to advantage in studies of RA, cancer, and autism, ${ }^{3,4}$ in which some of the observed clusters within the population could have occurred simply by chance. Genealogic studies may be sufficient to establish the familial clustering of a common disease. In this situation, it is possible, generally, to detect smaller risk differences than may be observable using other sampling schemes. Although genealogic studies involve substantial labor and large budgets, they have advantages and potential that is not available using other genetic epidemiologic approaches.

\section{RA in the Pima Indians}

The Pima Indians of the Gila River valley are a relatively isolated population, currently numbering approximately 15,000 individuals. ${ }^{5}$ The majority of the Pima reside in the Gila River Indian Community in Arizona, centered approximately 50 miles southeast of the Phoenix metropolitan area. The Pima Indians of today are believed to have descended from the Hohokam, who inhabited the Gila and Salt River valleys for more than 2,000 years. "The ancestors of the Hohokam, thought to be Paleo-Indians, descended from the first of two or three migrations across the Bering land bridge from Asia to North America between 16,000 to 40,000 years ago. ${ }^{7-9}$ There had been very little admixture of the Pima with other ethnic groups until the 19th century, when settlement of Europeans began to increase. Currently, it is estimated that $>80 \%$ of the alleles in this population are derived from the Pima or a closely-related tribe, the Tohono-O'odham, and $92 \%$ are derived generally from American Indian tribes. ${ }^{11}$

Differences in disease prevalence at the population level may suggest genetic influences on disease. Amerindians, especially the Pima, are known to have a very high prevalence of Type 2 diabetes mellitus and gallbladder disease, followed by Mexican Americans, Caucasians, and African Americans. ${ }^{1-15}$ In the Pima, the prevalence of Type 2 diabetes is inversely related to

Table 1

Inbreeding and consanguinity in the Pima Indians

\begin{tabular}{lccl}
\hline $\begin{array}{l}\text { Inbreeding } \\
\text { coefficient }\end{array}$ & $\begin{array}{c}\text { No. Inbred } \\
\text { individuals }\end{array}$ & $\begin{array}{c}\text { No. Consanguinity } \\
\text { relationship }\end{array}$ & $\begin{array}{c}\text { Relationship } \\
\text { between parents }\end{array}$ \\
\hline 0.0625 & 14 & 7 & First cousin (FC) \\
0.03125 & 5 & 3 & FC once removed \\
0.015625 & 9 & 6 & Second cousin (SC) \\
0.0078125 & 4 & 3 & SC once removed \\
0.00390625 & 3 & 1 & Half SC \\
Total & 3 & 2 & Third cousin \\
\hline
\end{tabular}

*Total number of marriages is 7,815 . the degree of Caucasian admixture. ${ }^{16} \mathrm{RA}$, another common, complex disease displays varying prevalence among Native American populations, with prevalence ranging from $3.4 \%$ to $8.2 \%$ in women as assessed by Rome criteria. The higher prevalence of RA in Amerindians, as compared with approximately $1 \%$ in Caucasian populations, ${ }^{17}$ may possibly be related to the presence of an Amerindian RA disease susceptibility epitope. ${ }^{18}$ Using traditional genetic epidemiologic methods, the occurrence of RA in the Pima population was postulated to be due to nongenetic effects. ${ }^{19,20}$ It was later learned that genetic factors, especially the Major Histocompatibility Complex (MHC) play an important role in RA risk..$^{21,22}$

We report here the application of large-scale genealogic information for studying complex traits, and take as example familial clustering of RA in an isolated population. We constructed a genealogy of the Pima population for use as a tool for genetic studies of the complex disorders that occur in high frequency in this population. We also analyzed the population to determine the coefficient of inbreeding, information that may be used for future studies of common diseases in the Pima.

\section{SAMPLING AND METHODS}

\section{Population demographics and genealogy construction}

Since 1965, a longitudinal epidemiologic study of arthritis and diabetes has been conducted in the Pima Indian population in the Gila River Indian Community. Demographic records are available for 22,862 individuals in the database during this 30 -year period and include epidemiologic study participants, their children, and deceased parents, population members outside the epidemiologic study area, and a limited number of non-Pima study participants.

We constructed a genealogy of the population using an algorithm developed to group all individuals with at least one member in common in his/her nuclear family into a pedigree. Each record, in addition to numerous demographic and clinical variables, contained an individual's ID as well as father's and mother's ID and was treated as a nuclear family. Any two nuclear families with at least one member in common were then linked.

We also used an algorithm to identify biological relationships among all RA cases as well as any two individuals' biological relationship in the same pedigree. Similar to the methods used by Cormen et al., ${ }^{23}$ starting with each individual, the population demographic database was searched for the ancestors of that person and their forebears until the top of the line of ascent was reached. Subsequently, for each ancestor identified in this way, the database was searched downward for all descendants of each ancestor.

\section{Rheumatoid arthritis case definition and ascertainment}

For the purpose of a genetic study, we wished to be conservative in our classification of individuals as affected. We therefore identified only those individuals with a "definite" diagnosis of RA. From 1965 to 1990, an RA case was defined as any individual who met the 1987 ACR (American College of Rheumatology) criteria for RA, and/or had sero-positive, 
erosive disease by Rome criteria for $\mathrm{RA}^{24}$ (criteria known to be associated with severe disease). ${ }^{25}$ More than 4,850 individuals who were half- to full-blooded Pima and/or Tohono O'odham Indians aged $\geq 20$ years and who participated in the longitudinal epidemiologic study of arthritis formed the population used for this study.

\section{Population subsample selection}

Four thousand subsamples ( $\mathrm{n}=88$, the number of RA cases identified) of the entire study population were selected to establish an empirical distribution. These population subsamples were selected randomly from the population of individuals who met the same demographic profile as RA cases, i.e., participated in the epidemiologic study, were $\geq 50 \% \mathrm{Pima} /$ Tohono O'odham, and were age-matched within a 10 -year interval with RA cases. The same method as discussed above was used to determine the biological relationship among all possible pairs of individuals within each set of the population subsample.

\section{DATA ANALYSIS}

The kinship coefficient between two individuals is defined as the probability that a gene taken at random from one individual at a given locus is identical by descent to a gene taken at random from another individual at the same locus. ${ }^{26}$ The smaller the kinship coefficient, the lower, on average, the probability that the two individuals share genes that are identical by descent, and thus the more distant the genetic relationship. By definition, if two individuals are unrelated, the kinship coefficient is zero.

$$
k\left(B_{1}, B_{2}\right)=\Sigma_{A} \Sigma_{p}(1 / 2)^{n(A, p)+m(A, p)+1}[1+F(A)]
$$

where $k\left(B_{1}, B_{2}\right)$ is the kinship coefficient between individuals $B_{1}$ and $B_{2} ; A$ is a common ancestor of $B_{1}$ and $B_{2} ; P$ is a path from $B_{1}$ to $B_{2}$ via a common ancestor $A ; n$ is the number of meiotic events between $A$ and $B_{1}$ and $m$ between $A$ and $B_{2}$; and $\mathrm{F}(\mathrm{A})$ is the probability that a common ancestor $A$ has two identical genes at a given locus.

The kinship coefficients were calculated for all possible pairs of RA cases $(3,828)$ then summed. The kinship coefficient for each of the 4,000 population subsamples was calculated in the same manner. The mean kinship coefficient across all 4,000 sets of population subsamples was determined by adding the sum of kinship coefficient for each subsample and dividing by 4,000 .

The null hypothesis was that the kinship coefficient for the RA cases was not different from the mean kinship coefficient of the population subsamples. Empirical kinship coefficients for the 4,000 population subsamples were plotted against that of the RA cases. The $p$ value was determined by calculating the proportion of the kinship coefficients of the population subsamples that were greater than that observed among the RA cases. Assuming that there were 20 population subsamples for which the kinship coefficient was greater than that of the RA cases, the $p$ value would be $20 / 4000=0.005$.

The progeny of consanguineous parents is, by definition, inbred. The impact of inbreeding is to increase the likelihood of homozygosity at each autosomal locus. We also used a new software program, KININB (unpublished data, 1999), which is based on the original path-counting method of Wright ${ }^{26}$ to identify all inbred individuals in the population and determine their inbreeding coefficients and the average inbreeding coefficient for the entire population. Average inbreeding in this population was calculated by 27

$$
\alpha=\Sigma p_{1} F_{1}
$$

where $p$ is the relative frequency of inbred individuals with inbreeding coefficient $F$. This is actually estimated from marriages between related individuals rather than from progeny.

\section{RESULTS}

Among the 22,862 records, 15,560 of them could be linked, either through a biological relationship or marriage, into a single large seven-generation pedigree; the remaining formed different sized pedigrees. No single pedigree could be traced further than seven generations. In the entire demographic data set, there were 7,815 marriages with an average of 1.11 and 1.23 for males and females, respectively. In the single seven-generation pedigree, there were 3,315 founders (persons on whom no ancestral data were available in the database), and the average number of marriages was 1.16 and 1.33 for males and females, respectively. From this genealogy, the relationship, either biological or through marriage, between any two individuals could be established, if such a relationship existed. Because each individual had a unique ID, there was no problem with consistency, as could occur if names were used as identifiers.

Using the diagnostic criteria as defined, the total number of RA cases identified was 88: 69 women, mean age (at time of study) $54.9 \pm 14.2$ years; and 19 men, mean age $59.8 \pm 16.1$ years. ${ }^{24}$ Forty of the $88 \mathrm{RA}$ cases were related as second-cousins or closer: three grandparent-grandchild pairs, nine parentoffspring pairs; seven sib-sib pairs; eight cousin-cousin pairs ( 1 st through 2 nd); and 11 avuncular pairs. The remainder were either sporadic cases or linked beyond the familial relationship that could be identified from the genealogy.

The sum of the kinship coefficients among all possible RA pairs was 5.92. The mean kinship coefficient across all 4,000 population subsamples was $1.99 \pm 0.64$, which was less than one-third of that for the RA cases. The empirical distribution of the kinship coefficient of the 4,000 populations subsamples is shown in Figure l. None of the kinship coefficients of the subsamples of the population was greater than that of the RA cases. The empirical $p$ value is $0 / 4000=0$, with an upper $95 \%$ percent confidence limit of 0.00092 .

For convenience, we plotted the distribution of kinship exponents rather than the actual kinship coefficient. A "kinship exponent" of 2 represents the kinship coefficient of sibling pairs or parent-offspring pairs $\left(1 / 2^{2}\right)$. Likewise, a kinship exponent of 4 would most commonly represent first-cousin pairs $\left(1 / 2^{4}=\right.$ $1 / 16$ ). Figure 2 presents the comparison between the pairs of individuals in each kinship coefficient class for RA cases, and the mean number of pairs in each kinship coefficient class aver- 


\section{Empirical Kinship Coefficient Distribution (4000)}

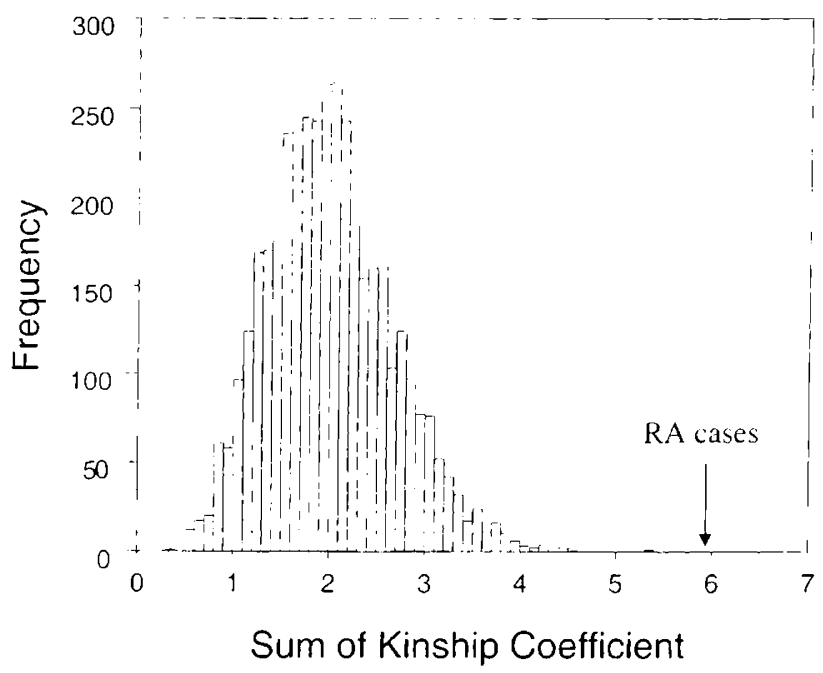

Fig. 1 Empirical kinship coefficient distribution of $4,(1)(1)$ xets of population subsamples. The $x$ axis is the sum of kinship coctficient af cach population subsample set; the 1 axis is the corresponding frequency.

aged across all 4,000 population subsamples. This comparison shows that the kinship coefficients of RA cases are higher than that of population subsamples in all classes.

We also investigated the rate of inbreeding in the population. Among the 22,862 individuals, 38 individuals were inbred, resulting from 22 consanguineous marriages. All occurred in the single large pedigree of 15,560 individuals. None of the 38 inbred individuals had RA. These results are presented in Table 1. Among the 38 inbred individuals, 18 were male and 20 female. Their ages fell between 2 and 40 years, and were distributed quite evenly, suggesting that marriage patterns have not changed substantially during the time this analysis encompasses. The average inbreeding coefficient calculated on the total database was 0.00009 , and 0.00019 for the single large pedigree. Both values were calculated under the assumption that all founders' inbreeding coefficients were zero.

\section{DISCUSSION}

Our genealogic study of RA in the Pima showed that the average kinship coefficient among all RA cases was three times higher than that of subsamples from the entire population, a difference significant at $p<0.001$. This finding indicates that RA in the Pima has a measurable familial component. This familiality could be due to factors that are genetic, environmental, or a combination of both. However, as shown in Figure 2, the kinship coefficients of RA cases were elevated over that of matched population subsamples at all levels of biological relationship up to second cousin. Because familial aggregation due to common environment usually occurs at the level of first-degree relatives and is greatly diluted at more distant biological relationships, it is unlikely that common environment could explain the observed level of familial aggregation in this population. Our results, therefore, support the hypothesis of a genetic component in the development of RA in the Pima Indians. This finding is consistent with many studies of RA in other populations. ${ }^{28-30}$ Past studies of the genetics of RA came to different conclusions about the contribution of major genes. RA has been proposed to be caused by a recessive major gene, ${ }^{31}$ a dominant gene with incomplete penetrance, ${ }^{32}$ two genes, ${ }^{3.3}$ and polygenes. ${ }^{34}$ In any case, these studies support the hypothesis that RA susceptibility has a complex genetic basis. One common finding across many studies is that HLA plays an important role in susceptibility to RA. ${ }^{22,35} \mathrm{~A}$ recent genome-wide linkage study estimated that alleles at the HLA locus account for at least one-third of the genetic component of RA susceptibility. ${ }^{36}$

An earlier study of RA in the Pima ${ }^{19}$ failed to detect significant familial aggregation. However, this study used the sibpair method of Penrose ${ }^{37}$ as extended by Cotterman, ${ }^{38}$ which is based on the comparison of observed and expected distributions of three kinds of sib-pairs; affected-affected, affectedunaffected, and unaffected-unaffected under different genetic hypotheses. In this way, all information beyond the nuclear family was lost. However, there were many biological relationships beyond sib-pairs or simple nuclear families that were available for analysis in this population, as detected by our methods. Among 22,862 study individuals, 15,560 are linked through either a biological or marital relationship into a single large pedigree with seven generations. In addition, most of the remaining individuals in the population can be linked into large, multi-generational pedigrees as well. The current study was conducted on the entire population and could detect all possible biological relationships within the data. Also, comparing our results with those of the previous study limited to 


\section{Distribution of Kinship Exponent}

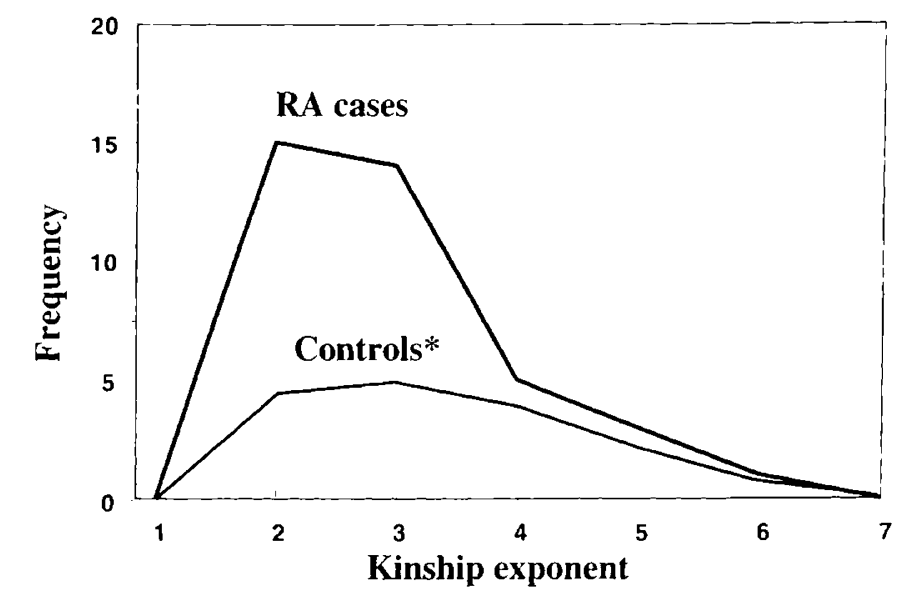

*The control curve is the average of $\mathbf{4 0 0 0}$ sets of control groups

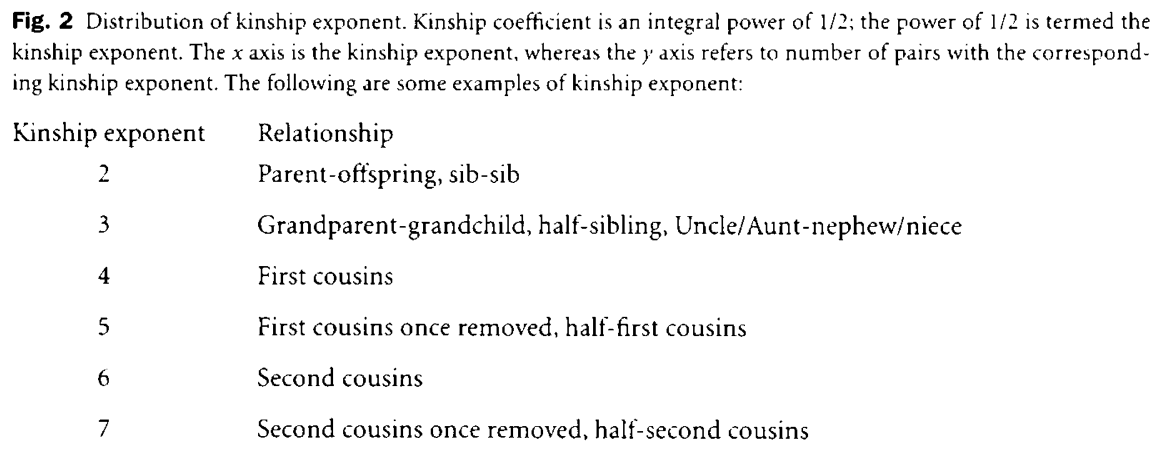

nuclear families, one may conclude that, in addition to HLA, which appears to play an important role in RA, there may also be a strong polygenic effect. For polygenic type of causation, genetically distant relationships could contribute a relatively important risk to the entire picture. Our study was not designed to identify the specific gene(s) or even the inheritance model for RA, however, but to apply an alternative approach to searching for familial aggregation. These results may then pave the way for further genetic studies in RA, including genome screening to identify RA-risk loci.

Because more than two-thirds of the population could be linked into a single large pedigree, and the Pima are relatively isolated genetically, one might expect that inbreeding in the population would be high. Additionally, considering the postulated recessive factors in $\mathrm{RA},{ }^{31}$ one might also expect significantly higher rates of consanguinity among the parents of RA cases. Rather, our results showed that the average inbreeding coefficient in the Pima was 0.00009 and 0.00019 for the entire population and the single large pedigree, respectively. Both of these estimates are no higher than the average reported in most human populations. ${ }^{27}$ Our finding of low rates of inbreeding in this population is consistent with the traditional prohibition against marrying close relatives, specifically second-cousins or closer, among the Pima. ${ }^{39}$ Our inbreeding estimate in the Pima is dependent on the quality of reported marriage and parentage data and the limitation to seven generations of data availability. We identified no inbred RA cases, but this finding may be due to the fact that the average age of an RA case was 56 years; therefore, many affected individuals may not have had sufficient ancestor data available for inbreeding to be detected. Thus, we may have underestimated the total inbreeding in the population. However, similar situations have occurred in other populations where estimates of inbreeding were computed $^{26}$ and relationships more remote than third cousins were rarely included in the computation. Because the ability to detect inbreeding is dependent on the pedigree depth, this may explain why all inbred individuals were detected only in the large pedigree, whereas other pedigrees may not have been large enough to detect distant relationships.

Studies of complex diseases may be complicated by age and/or sex-dependent penetrance, genetic heterogeneity, and geneenvironment interactions. Studies of the familiality of common diseases therefore may give false negative results when they are underpowered, and in those cases the genealogical methodology may give a more accurate result. The advantages of using a genealogic approach to investigate complex disease 
include: (1) Use of the whole population as a unit and thus all information available regarding biological relationships. In our study, even though there are only relatively few cases of RA, the genealogic method detected the presence of familial aggregation; in a population like this with a few cases of complex disease, other traditional genetic epidemiologic methods would not have had enough power to detect familial aggregation. (2) Minimization of ascertainment bias because the whole population is surveyed, rather than ascertaining through affected probands. Additionally, it can be highly advantageous to study isolated populations in which there may be founder effects. ${ }^{40,41}$ A disease-causing mutation that is introduced by a few founders into a population, and subsequently expands in relative isolation, may be flanked by tightly linked markers that will be inherited together. This characteristic can be exploited efficiently using linkage disequilibrium techniques in gene mapping. The high frequency of RA in the Pima, genetic characteristics of the community, and the particularly high frequency of the RA epitope ( $94 \%$ of the Pima carry the RA epitope, HLA Dr $\beta 1^{*}$ $1402^{10}$ ) make this population a tempting target in which to search for non-HLA RA-susceptibility loci that are hypothesized to account for approximately one-half of the familial susceptibility to RA. ${ }^{42,43}$ Finally, the genealogic approach can provide details about the level of inbreeding in the population. This information may contribute to our understanding of the genetic basis of the disease.

The creation of the Pima genealogy can be anticipated to provide valuable information for the genetic studies of other diseases in this population. More importantly, the concept of defining the population, if it is relatively homogeneous and isolated, as the unit in which to assess "familial aggregation" has proved to be a powerful method for studying complex diseases, especially when a study population is limited by a relatively small number of cases.

\section{References}

1. Levin SE, Herman AA, Irwig LM. Systolic blood pressure differences in black, colored and white infants. Am J Epidemiol 1987;125(2):221-230.

2. Bishop DT, Skolnick MH. Genetic epidemiology of cancer in Utah genealogies: A prelude to the molecular genetics of common cancers. / Cell Phisiol Suppl 1984;3:63-77.

3. Jorde LB, Mason-Brothers A, Waldmann R, Ritvo ER, Freeman BI, Pingree C, McMahon WM, Petersen B, Jenson WR, Mo A. The UCLA-University of Utah epidemiologic survey of autism: Genealogical analysis of familial aggregation. Am J Med Genet 1990;36:85-88.

4. Hill JR. A survey of cancer sides by kinship in the Utah Mormon population. In: Cairns I, Lyon IL, Skolnick MH, editors. Cancer Incidence in Defined Populations, Banbury Report 4. New York: Cold Spring Harbor Laboratory, 1980:299-318.

5. U.S. Bureau of the Census. Top 25 American Indians tribes for the United States: 1990 Census. $1997 \mathrm{http}: /$ www.census.gov/population/socdemo/race/indian/ailangl.txt

6. Haury EM, editor. The Hohokam. Desert farmers and craftsmen, excavations at Snaketown, 1964-1965. Tuscon: University of Arizona Press, 1976.

7. Wallace DC, Garrison K, Knowler WC. Dramatic founder effects in Amerindian mitochondrial DNAs. Am I Physiol Anthropol 1985;68:149-155.

8. Williams RC, Steinberg AG, Gershowitz H. Bennett PH, Knowler WC, Pettitt DJ, Butler W, Baird R, Dowda-Rea L. Burch TA, Morse HG, Smith CG. Gm allotypes in native Americans: Evidence for three distinct migrations across the Bering land bridge. Am / Physiol Anthropol 1985;66:1-19.

9. Gibbons A. The peopling of the Americas. Science 1996;274:31-32.

10. Williams RC, Knowler WC, Pettitt DJ, Long IC, Rokala DA, Polesky HF, Hackenberg RA, Steinberg AG, Bennett PH. The magnitude and origin of European-American admixture in the Gila River Indian Community of Arizona:
A union of genetics and demography. Am / Hum Genet 1992;51:101-110.

11. Sampliner RE, Bennett PH, Comess LJ, Rose FA, Burch TA. Gallbladder disease in Pima Indians: Demonstration of high prevalence and early onset by cholecystography. N Engl/ Med 1970;283:1358-1364.

12. Henrard I, Bennett PH, Burch TA. Rheumatoid arthritis in the Pima Indians of Arizona: An assessment of the clinical components of the New York criteria. Int I Epidcmiol 1975:4:119-126.

13. Knowler WC, Bennett PH, Hamman RF, Miller M. Diabetes incidence and prevalence in Pima Indians: A 19-fold greater incidence than in Rochester, Minn. Am J Epidemiol 1978;108:497-504.

14. Hanis CL, Chakraborty R, Ferrell RE, Schull WJ. Individual admixture estimates: Disease associdtions and individual risk of diabetes and gall bladder disease among Mexican-American in Starr County, Texas. A m / Physiol 1986;70:433-441.

15. Chakraborty R, Weiss KM. Frequencies of complex diseases in hybrid populations. Am J Physiol Anthropol 1986;70:489-503.

16. Knowler WC, Williams RC, Pettitt DJ, Steinherg AG. GM3,5,13,14 and type 2 diabetes mellitus: An association in American Indians with genetic admixture. Am I Hum Genet 1988:43:520-526.

17. Silman AJ, Hochberg MC, editors. Epidemiology of the Rheumatic Diseases. Oxford: Oxford Medical Publications, 1993.

18. Williams RC, Jacobsson LTH, Knowler WC, del Puente A, Kostyu D, McAuley IE, Bennett PH, Pettitt DI. Meta-analysis reveals association between most common class II haplotype in full-heritage Native Americans and rheumatoid arthritis. Hum Immunol 1995;42:90-94.

19. O'Brien WM, Bennett PH, Burch TA, Bunim II. A genetic study of rheumatoid arthritis and rheumatoid factor in Blackfeet and Pima Indians. Arthritis Rheum 1967;10:163-179.

20. Bennett PH, Burch TA. The distribution of rheumatoid factor and rheumatoid arthritis in the families of Blackfeet and Pima Indians. Arthritis Rheum 1968;11:546-553.

21. Rigby AS. HLA haplotype sharing in RA sibships: Risk estimates in siblings. Scand I Rhe umatol 1992;21:68-73.

22. Hasstedt SI. Clegg DO, Ingles L, Ward RH. HLA-linked rheumatoid arthritis. Am J Hum Genet 1994;55:738-746.

23. Cormen T, Leiserson C, Rivest R. Introduction to Algorithms. Boston: MIT, 1990

24. Hirsch R, Lin J-P, Scott WW, Ma LD, Pillemer SR, Kastner DL, Jacobsson LTH, Bloch DA, Knowler WC, Bennett PH, Bale SI. Rheumatoid arthritis in the Pima Indian families: The intersection of epidemiologic, demographic and genealogic data. Arthritis Rheum 1998:41:1464-1469.

25. Trentham DE. Rheumatic Disease Clinics of North America: Diagnostic Issues. Philadelphia: W. B. Saunders, 1994;309-319.

26. Wright S. Coefficients of inbreeding and relationship. Am Nat 1922:56:330-338.

27. Cavalli-Sforza LL, Bodmer WF. The Genetics of Human Population (Chapter 7). Inbreeding. San Francisco: W.H. Freeman and Company, 1971:342-385.

28. Lawrence IS. Rheumatoid arthritis-nature or nurture? Ann Rhewm Dis $1970 ; 29: 357-379$

29. Yamashita TS, Khan MA, Kushner I. Genetic analysis of families with multiple cases of rheumatoid arthritis. Dis Markers 1986:4:113-119.

30. Deighton CM. Walker DI The familial nature of rheumatoid arthritis. Ann Rheum Dis 1991:50:62-65.

31. Lynn AH, Kwoh CK, Venglish CM, Aston CE, Chakravarti A. Genetic epidemiology of rheumatoid arthritis. Am / Hum Ginet 1995:57:150-159.

32. Yamashita TS, Khan MA, Kushner I. Genetic analysis of families with multiple cases of rheumatoid arthritis. Dis Markers 1986;1:113-119.

33. Righy AS, Voelm L, Silman AI. Epistatic modeling in rheumatoid arthritis: an application of the Risch theory. Genet Epidemiol 1993;10:311-320.

34. Prichard MA. Evidence for a hypothetical non-HLA susceptibility gene in rheumatoid arthritis. Br I Rheumatol 1994:33:457-479.

35. Kawahito Y, Cannon GW', Gulko PS, Remmers EF, Longman RE, Reese VR, Wang J. Griffiths MM, Wilder RL. Localization of quantitative trait loci regulating adjuvant-induced arthritis in rats: Evidence for genetic factors common to multiple autoimmune diseases. J Immunol 1998;161:4411-4419.

36. Cornelis F, Faure S, Martinez M, Prud homme J-F, Fritz P, Dib C, Alves H, Barrera P. Vries ND, Balsa A, Pascual-Salcedo D, Maenaut $K$, Westhovens R, Migliorini P, Tran T-H, Delaye A, Prince N, Lefevre C, Thomas G, Poirier M, Soubigou S. Alibert O, Lasbleiz S, Fouix S, Bouchier C, Liote F, Loste M-N, Lepage V, Charron D, Gyapay G. Lopes-Vaz A, Kuntz D, Bardin T. Weissenbach J. New susceptibility locus for rheumatoid arthritis suggested by a genome-wide linkage study. Proc Nat Acad Sci USA 1998:95:10746-10750.

37. Penrose LS. The detection of autosomal linkage in data which consist of pairs of brothers and sisters of unspecified parentage. Ann Eugen 1935;6:133-138.

38. Cotterman $\mathrm{CW}$. Indication of unit factor inheritance in data which consist of pairs of brothers and sisters of unspecified parentage. Ohio J Sci 1937;37:127.

39. Ortiz A. Southwest. Handbook of North American Indians. Volume 10. Washing- 
ton, DC: Smithsonian Institution, 1483

40. Levy EN, Shen Y, Kupclian A. Kruglyak L, Aksentijevich I. Pras E, Balow, Jr. JE, Linzer B, Chen X, Shelton DA, Ciumucio D, Pras M, Shohat M, Rotter II, Fischel-Ghodsian N, Richards RI, Kastner DL. Linkage disequilibrium mapping places the gene causing familial Mediterranean fever cluse to D16S246. Am / Hum Ginct 1996;58:523-534.

41. Nystuen A, Benke PI, Merren I, Stone EM, Sheffield VC. A cerebellar ataxia locus identified by DNA pooling to search for linkage disequilibrium in an isolated population from the Cayman Islands. Hum Mol Genet 1996;5/4):525-531.

42. Rigby AS, Voelm L, Silman AJ. Epistatic modeling in rheumatoid arthritis: An application of the Risch theory. Genet Epidemiol 1993;10:311-320.

43. Remmers EF, Longman RE, Du Y, O'Hare A, Cannon GW, Griffiths MM, Wilder RL. A genome scan localizes five non-MHC loci controlling collagen-induced arthritis in rats. Nat Genet 1996:14:82-85.

\section{Erratum}

The authors names and affiliations for "Issues in implementing prenatal screening for cystic fibrosis: Results of a working conference" (Genetics in Medicine May/June 1999:129-135) were printed incorrectly. The correct list of authors and their affiliations is as follows:

James E. Haddow, $M D^{l}$, Linda A. Bradley, PhD', Glenn E. Palomaki, BS ${ }^{l}$, Richard A. Doherty, $M D^{l}$, Barbara A. Bernhardt, $M S^{2}$, David J. H. Brock, $P h D^{3}$, Brian Cheuvront, PhD ${ }^{4}$, George C. Cunningham, $M D^{5}$, Alan E. Donnenfeld, $M D^{6}$, Jeryl L. Erickson, $M S^{1}$, Henry A. Erlich, PhD $D^{7}$, Richard M. Ferrie, PhD $D^{8}$, Stacey C. FitzSimmons, PhD ${ }^{9}$, Michael F. Greene, MD ${ }^{10}$, Wayne W. Grody, MD, PhD ${ }^{11}$, Paula K. Haddow, MAT', Hilary Harris, $M D^{12}$, Lewis B. Holmes, $M D^{13}$, R. Rodney Howell, $M D^{14}$, Michael Katz, MD ${ }^{15}$,

Katherine W. Klinger, PhD ${ }^{16}$, Edward M. Kloza, MS ${ }^{1}$, Michael L. LeFevre, MD, MSPH ${ }^{17}$, Stephen Little, PhD Greg Loeben, $P h D^{18}$, Margaret McGovern, $M D, P h D^{19}$, Reed E. Pyeritz, $M D, P h D^{20}$, Peter T. Rowley, MD ${ }^{21}$, Randall K. Saiki, BS , M. Priscilla Short, MD'2, John Tabone, PhD ${ }^{23}$, Nicholas J. Wald, FRCP', Nachama L. Wilker, $B A^{25}$, David R. Witt, $M D^{26}$

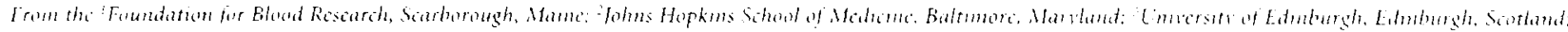

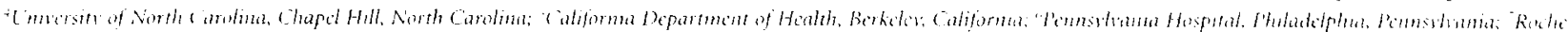

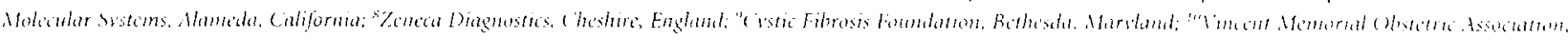

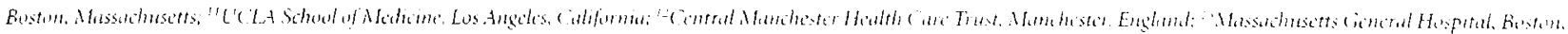

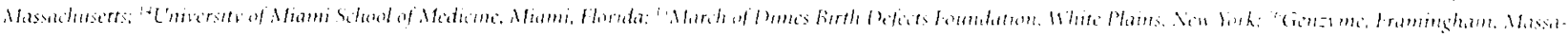

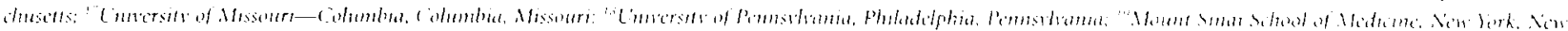

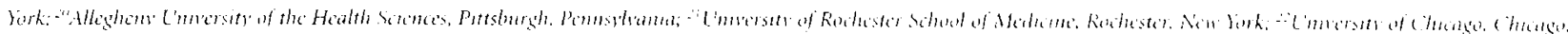

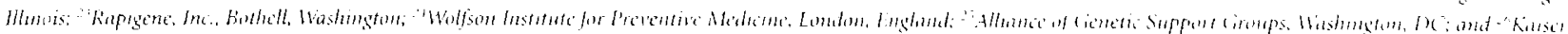

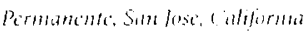

